\title{
Selective Inhibition of Axon Outgrowth by Antibodies to NGF in a Model of Temporal Lobe Epilepsy
}

\author{
David M. Holtzman' and Daniel H. Lowenstein ${ }^{2}$ \\ 'Department of Neurology, Center for the Study of Nervous System Injury, and the Alzheimer's Disease Research \\ Center, Washington University School of Medicine, St. Louis, Missouri 63110 and ${ }^{2}$ Departments of Neurology and \\ Anatomy and the Neuroscience Program, University of California at San Francisco, San Francisco, CA 94143
}

\begin{abstract}
The molecular basis of the axonal reorganization that follows seizure-induced brain injury is unknown. Elevations in neurotrophins following seizures suggest that growth factors may play a role in this process. After pilocarpineinduced seizures, robust axonal sprouting from dentate granule cells and cholinergic forebrain neurons was evident in the inner molecular layer of the dentate gyrus. Intraventricular infusions of an NGF-specific antibody that blocks NGF biological activity in vitro attenuated the cholinergic axonal sprouting and the increases in cell body size of basal forebrain cholinergic neurons that followed seizure-induced injury in vivo. In contrast to its effects on the cholinergic network, the NGF antibody did not decrease the sprouting of dentate granule cell axons into the inner molecular layer. These results suggest that NGF may have a functional and system-specific role in the remodeling of networks that follows repetitive seizures.

[Key words: nerve growth factor, neurotrophin, neurotrophic factor, epilepsy, seizures, sprouting]
\end{abstract}

The molecular mechanisms that contribute to the pathogenesis of spontaneous, recurrent seizures (epilepsy) are unknown. Epileptic disorders are divided into several subgroups, among which temporal lobe epilepsy (TLE) is one of the most common (Engel, 1989). Much of what we know about TLE comes from electrophysiological and pathological studies of hippocampi from patients and animal models. The most frequent lesion seen in humans with TLE is mesial temporal sclerosis (Margerison and Corsellis, 1966). Pathologically, there is often loss of subpopulations of neurons in CA1, CA3, and the hilus of the dentate gyrus (Margerison and Corsellis, 1966; Gloor, 1991; Meldrum and Bruton, 1992). In addition, there is abnormal axonal sprouting of particular neuronal systems. The system studied most extensively has been the projections of the dentate granule cells (i.e., mossy fibers), which have been shown to reorganize in both animal models and humans with TLE (Nadler et al., 1980; Tauck

\footnotetext{
Received Apr. 12, 1995; revised July 18, 1995; accepted July 20, 1995

We thank William Mobley for providing anti-NGF and NGF, and James Conner for providing the antibody for NGF immunocytochemistry. We thank Drs. Mobley, Helen Scharfman, and Robert Sloviter for many useful discussions and critical review of the manuscript. These studies were supported by National Institutes of Health Grants NS32062 (D.H.L.), AG00445 (D.M.H.), and NS32553 (D.M.H.), the Esther A. and Joseph Klingenstein Fund (D.I.L.), and a National Down Syndrome Scholarship (D.M.H.)

Correspondence should be addressed to Daniel H. Lowenstein, M.D., Department of Neurology, Box 0114 , University of California at San Francisco, San Francisco, CA 94143

Copyright (C) 1995 Society for Neuroscience $0270-6474 / 95 / 157062-09 \$ 05.00 / 0$
}

and Nadler, 1985; Babb et al., 1991; Houser, 1992). In particular, there is aberrant sprouting of mossy fiber axons into the inner third of the molecular layer (stratum moleculare) of the dentate gyrus, which is presumed to occur as a result of seizure-induced loss of cells that normally innervate this lamina. Electron microscopic studies have provided evidence that at least some of these mossy fibers make direct contacts with dentate granule cells (Laurberg and Zimmer, 1981; Franck et al., 1995). It is also now recognized that other fiber systems reorganize as well, including those derived from GABAergic and cholinergic neurons (Green et al., 1989; Davenport et al., 1990). It is therefore very likely that the type and extent of sprouting ultimately modifies hippocampal excitability and thus sprouting has been considered as one potential mechanism underlying TLE. The possible role of sprouting in epileptogenesis has led us to investigate the spectrum and sequence of molecular events that mediate this process.

In order to study seizure-induced sprouting, many investigators have used the pilocarpine or kainate model of status epilepticus in rats. In these models, systemic administration of a convulsant drug leads to several hours of repetitive seizures. This is followed by cell loss and a specific pattern and time course of degeneration and synaptic reorganization within the hippocampus that shares many of the features seen in humans with TLE (Nadler et al., 1980; Tauck and Nadler, 1985; Mathern et al., 1992; Mello et al., 1993; Franck et al., 1995). Although the mechanisms that initiate and mediate axonal sprouting following seizures are unknown, it has been hypothesized that growth factors play a role in this process (Gall, 1993).

Neurotrophins are structurally related polypeptides that make up one family of growth factors (Thoenen, 1991). Nerve growth factor (NGF) is the best characterized member of this family, which also includes brain-derived neurotrophic factor (BDNF), neurotrophin-3 (NT-3), and NT-4/5 (Thoenen, 1991; Chao, 1992). It is clear that these molecules play a critical role in the survival and maintenance of neurons in the peripheral nervous system (PNS) (Snider, 1994). In addition, they are expressed in the developing and adult CNS where they may play similar yet distinct roles (Ernfors et al., 1990b; Phillips et al., 1990).

Experiments from several laboratories have shown that the mRNAs of the neurotrophins NGF, BDNF, and NT-3 are expressed within neurons of the hippocampus (Large et al., 1986; Ernfors et al., 1990a; Phillips et al., 1990). Although their temporal patterns of expression differ, NGF and BDNF transcripts are increased for hours or longer following limbic seizures induced by an electrolytic lesion of the dentate gyrus hilus (Gall and Isackson, 1989; Gall, 1993; Pico and Gall, 1994), convulsant 
duses of kainic acid (Dugich-Djordjevic et al., 1992), and direct electrical stimulation (Ernfors et al., 1991; Isackson et al., 1991; Bengzon et al., 1992). Interestingly, NGF protein and bioactivity are increased for weeks to months after kainate or kindlinginduced seizures (Bengzon et al., 1992; Lowenstein et al., 1993). These observations of seizure-induced changes in the expression of neurotrophins, the time course of these changes, and the recent progress in the identification of the targets of these growth factors suggest that alterations in trophic communication may play a role in synaptic reorganization seen in the epileptic brain.

In this study, we have carried out a series of experiments aimed at furthering our understanding of the biochemical mechanisms of seizure-induced axonal reorganization. We sought to take advantage of our previous observation showing that the increased NGF-like bioactivity in the hippocampus following seizures can be blocked effectively in vitro by a highly specific anti-NGF antibody (Lowenstcin et al., 1993). Thus, the antiNGF antibody offered a potential means for directly testing in vivo how the expression of NGF following seizures contributes to changes in the different neuronal systems that are modified after seizure-induced injury. The study was therefore designed to address three specific questions: first, what are the patterns of seizure-induced axonal reorganization in the dentate granule cell mossy fibers as compared to fibers projecling into the dentate gyrus from basal forebrain cholinergic neurons? Second, are the newly sprouted dentate granule cell mossy fibers that occupy the inner molecular layer immunoreactive for NGF? Finally, does chronic, intraventricular infusion of an anti-NGF antibody selectively alter seizure-induced axonal reorganization within the dentate gyrus?

\section{Materials and Methods}

Animal preparation and chemoconvulsions. Adult male Fisher rats (Bantin and Kingman), weighing 220-250 gm at the time of seizure induction, were used for all studies. All protocols were approved by the Committees on Animal Research at the University of California, San Francisco. For induction of status epilepticus, animals were first injected with methylatropine $(1 \mathrm{mg} / \mathrm{kg}$ intraperitoneally, i.p.) followed $15 \mathrm{~min}$ later by pilocarpine $(320 \mathrm{mg} / \mathrm{kg}$, i.p.). Status epilepticus began $45-60$ min following injection of pilocarpine. Only animals having subsequent, continuous seizures were used in the "status epilepticus" group. In order to prevent the relatively high mortality associated with prolonged seizures, diazepam $(10 \mathrm{mg} / \mathrm{kg}$ intramuscularly) was injected $4 \mathrm{hr}$ after the onset of status epilepticus. This caused the seizures to subside within 10-15 min. Animals were monitored continuously following onset and until termination of status epilepticus. Animals were then monitored daily with most receiving subcutaneous injections of approximately 10 $\mathrm{ml}$ per day of $0.9 \%$ normal saline for the first $3 \mathrm{~d}$ following status epilepticus in order to prevent dehydration. The control or "no status epilepticus" group was derived from two sources. The first consisted of animals receiving no intervention. The second was from animals that received the methylatropine and pilocarpine but showed no behavioral manifestations of seizures and no subsequent evidence of seizure-induced injury or sprouting. The clinical and histopathological findings in these two subsets of controls were entirely normal in all cases.

Intracerebroventricular infusion studies. Intracerebroventricular (i.c.v.) infusion pumps were implanted $48 \mathrm{hr}$ after the onset of status epilepticus. Surgery and i.c.v. infusions of antibodies, vehicle, or artificial CSF were performed exactly as described previously (Holtzman et al., 1994, 1995) with the following modifications: (1) paraffin was used to coat one-half of the surface of Alzet model 2002 miniosmotic pumps (Alza corp.) to decrease the flow rate to $0.25 \mu \mathrm{l} / \mathrm{hr}$, and (2) normal goat serum or goat anti-mouse NGF (anti-NGF) was diluted to a concentration of $20 \mu \mathrm{g} / \mu \mathrm{l}$ in artificial CSF before filling the minipumps.

Characterization and administration of NGF antibodies. The antiNGF used for the i.c.v. infusion studies is an antiserum produced in goats to NGF prepared by ion exchange chromatography, followed by gel filtration on Sephadex G75, as described previously (Mobley et al.,
1986). Anti-NGF has been characterized extensively and is highly specific for NGF as opposed to other neurotrophins (Crutcher et al., 1993; $\mathrm{Li}$ et al., 1995). A different antibody to NGF prepared by Conner et al. (1992) was used for immunocytochemical localization of NGF as described below.

Immunostaining and AChE histochemistry. Animals were anesthetized with sodium pentobarbital $(100 \mathrm{mg} / \mathrm{kg})$ and perfused through the aorta using a peristaltic pump delivering solutions at a rate of approximately $25 \mathrm{ml} / \mathrm{min}$. For animals in which tissue sections were analyzed with cresyl violet staining, mossy fiber staining, p75 ${ }^{\text {NGFR }}$ immunostaining, goat IgG immunostaining, and AChE histochemistry, the following sequence of perfusates was used: normal saline $(3 \mathrm{~min}), 0.37 \%$ sulfide solution, pH $7.3(5 \mathrm{~min})$, normal saline $(3 \mathrm{~min}), 2 \%$ paraformaldehyde in $0.1 \mathrm{M}$ sodium acetate, $\mathrm{pH} 6.5(3 \mathrm{~min})$ and $2 \%$ paraformaldehyde/ $0.1 \%$ glutaraldehyde in $0.1 \mathrm{M}$ borate, $\mathrm{pH} 8.5$ (30 min). For animals in which NGF-like immunoreactivity was assessed, fixation was performed as described previously (Conner et al., 1992). Brains were removed and postfixed overnight at $4^{\circ} \mathrm{C}$ in the fixative used for perfusion. Following dehydration in $20 \% \mathrm{w} / \mathrm{v}$ sucrose in $0.1 \mathrm{M} \mathrm{PO} 4$ buffer $(\mathrm{pH}$ 7.4), $40 \mu \mathrm{m}$ sections were cut on a freezing sliding microtome. Sections were processed for $\mathrm{p} 75^{\mathrm{NGFR}}$ immunostaining (Holtzman et al., 1992b), cresyl violet staining, and Timm stain (Sloviter, 1982) as described previously. In animals in which an i.c.v. cannula was implanted, detailed assessment was carried out only if there was clear evidence for i.c.v. penetration by the cannula and no disruption of the fimbria-fornix.

For assessment of goat IgG deposition following i.c.v. administration of anti-NGF or normal goat serum, free-floating $40 \mu \mathrm{m}$ sections were incubated for $30 \mathrm{~min}$ with $5 \%$ normal rabbit serum in $0.1 \mathrm{M}$ Tris-buffered saline (TBS, pH 7.6) at room temperature. Sections were washed three times with TBS and then incubated with biotinylated rabbit antigoat IgG for $1 \mathrm{hr}$ at room temperature (Vector labs). Sections were then washed three times with TBS and incubated with streptavidin-HRP for $\mathrm{I} \mathrm{hr}$ at room temperature according to instructions (Vector ABC Elite kit). Sections were then washed three times with TBS and developed with $0.05 \% 3,3$ diaminobenzidine (DAB) and $0.01 \% \mathrm{H}_{2} \mathrm{O}_{2}$ in TBS. Hippocampal sections were processed for $\mathrm{AChE}$ histochemistry as described previously (Holtzman et al., 1992a). Briefiy, 12 equally spaced sections throughout the hippocampal formation were rinsed three times with $0.1 \mathrm{M}$ maleate buffer $(\mathrm{pH} 5.7)$ and processed free floating in individual wells. At each staining session, sections were processed from animals that underwent the following treatments: (1) no status epilepticus and receiving $22 \mathrm{~d}$ of vehicle infusion i.c.v., (2) status epilepticus followed $48 \mathrm{hr}$ later by anti-NGF infusion for $22 \mathrm{~d}$, (3) status epilepticus followed $48 \mathrm{hr}$ later by normal goat serum infusion for $22 \mathrm{~d}$, and (4) status epilepticus alone. In some sessions, sections were processed from animals that did not experience status epilepticus and had i.c.v. infusions of NGF (625 ng/day) dissolved in artificial CSF, or anti-NGF infusions for $22 \mathrm{~d}$.

Assessment of AChE and mossy fiber density as well as p75 $5^{\text {NGF. }}$ immunoreactive (immunoreactivity) neuronal profiles. The relative density of AChE-positive fibers in the inner margin of the inner molecular layer of the dentate gyrus was sampled in 15 regions $(5$ in each of three separate coronal sections located between 2.8 and $4.5 \mathrm{~mm}$ posterior to bregma (Paxinos and Watson, 1986)). The density of AChE-positive fibers was assessed with the MCID image analysis system (Imaging Rescarch Inc., St. Catherines, Ontario) linked to a Leitz Aristoplan microscope (Leica, Inc., Foster City, CA). The mean number of pixels in 15 rectangles (height $20 \mu \mathrm{m} \times$ width $40 \mu \mathrm{m}$ ), which were covered by AChE fibers was determined in the right inner margin of the inner molecular layer of each animal. The sample areas all began at the top of the granule cell layer and extended at a $90^{\circ}$ angle to a height of 20 $\mu \mathrm{m}$ (see Fig. 2). The mean values obtained for each animal were compared to the mean values obtained in animals that did not sustain status epilepticus and received i.c.v. infusion of vehicle. Densities were expressed as a percentage of vehicle-treated animals processed in an identical fashion at the same time. Mossy fiber sprouting was assessed in a similar fashion, except that measurements of relative optical density rather than density of fibers were made since individual Timm stained mossy fibers are difficult to visualize. Measurement of the cross-sectional area of p75 ${ }^{\text {NGrR }}$-immunoreactive profiles in the medial septal nucleus was performed with the MCID image analysis system as described

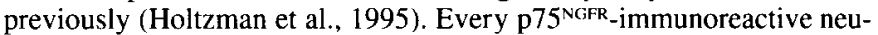
ronal profile with a nucleus was assessed in the medial septal nucleus in one coronal section $(0.2 \mathrm{~mm}$ anterior to bregma) from each animal 

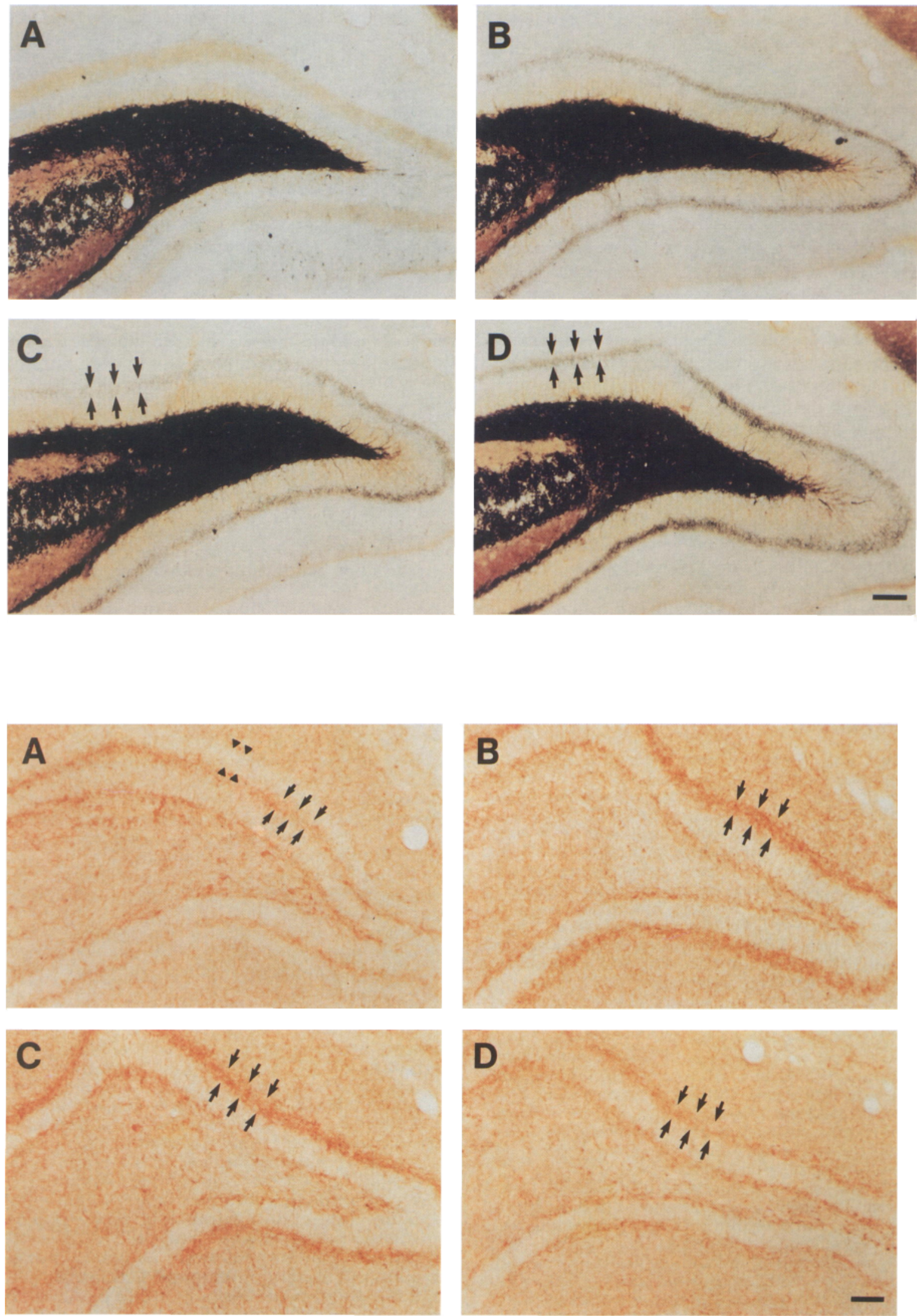

Figure 1. (top). Mossy fiber staining in the dentate gyrus before and after chemoconvulsant-induced status epilepticus. In the normal dentate gyrus $(A)$, mossy fibers are not present in the molecular layer. Twenty-four days following pilocarpine-induced status epilepticus $(B)$ there is mossy fiber sprouting into the inner third of the molecular layer. When comparing animals that sustained status epilepticus and received either i.c.v.-administered normal goat serum $(C)$ or anti-NGF $(D)$, there was no consistent difference in the amount of mossy fiber staining into the inner molecular layer. Scale bar in $D, 120 \mu \mathrm{m}$. 
if it was superior to a line between the anterior commissure and within $0.75 \mathrm{~mm}$ of the midline.

\section{Results}

Mossy fiber and cholinergic sprouting following

chemoconvulsant-induced status epilepticus

In the normal hippocampus, the axons of dentate granule cells (mossy fibers) innervate dentate hilar neurons and the proximal apical dendrites of CA3 pyramidal cells. Normally, there is little or no mossy fiber staining in the molecular layer of the dentate gyrus. Similar to results from previous studies (Nadler et al., 1980; Mello et al., 1993; Tauck and Nadler, 1985), we found that pilocarpine-induced status epilepticus led to prominent neuronal loss primarily in the dentate hilus and CA3 pyramidal layer, and reorganization of granule cell axons within the dentate gyrus. In particular, mossy fiber staining within the inner third of the molecular layer began to appear approximately 1 week following status epilepticus, and the staining was relatively robust by $24 \mathrm{~d}$ (Fig. 1A,B).

Cholinergic axons that originate from neuronal cell bodies in the medial septal nucleus and vertical limb of the diagonal band form a major projection system to the hippocampus (Coyle et al., 1983; Olton et al., 1991). These neurons (basal forebrain cholinergic neurons-BFCNs) send their terminals to all major regions of the hippocampus in a well-described laminar pattern (Lewis and Shute, 1967). In the dentate gyrus of the hippocampus, there is normally a dense plexus of cholinergic terminals in the outer molecular layer as well as in the inner margin of the inner molecular layer (Fig. 2A). However, there is a relative paucity of cholinergic terminals within the outer margin of the inner molecular layer (Fig. 2A). Twenty-four days after pilocarpine-induced status epilepticus, there was an obvious increase in the density of AChE stained fibers in the inner molecular layer (Fig. 2B). Similar results were obtained when seizures were induced by i.p. kainic acid $(10 \mathrm{mg} / \mathrm{kg}$ ) (data not shown). To confirm further that the AChE staining represented staining of BFCN axons, we also performed immunostaining for the low affinity NGF-receptor (p75 ${ }^{\mathrm{NGFR}}$ ) in the hippocampus following status epilepticus. $775^{\text {NGFR-immunoreactivity is colocalized spe- }}$ cifically to BFCN cell bodies (Hefti et al., 1986; Yan and Johnson, 1988), and p75 in the normal hippocampus mimics that seen for $\mathrm{AChE}$ staining (Gomez-Pinilla et al., 1987). Twenty-four days following status epilepticus, $\mathrm{p} 75^{\mathrm{NGFR}}$ fiber staining within the hippocampus was virtually identical to the AchE staining scen following status epilepticus in that there was now robust $\mathrm{p} 75^{\mathrm{NGFR}}$ immunoreactivity within the inner molecular layer (data not shown).

\section{NGF-like immunoreactivity is altered following status epilepticus}

The molecular basis for the system-specific sprouting within the hippocampus following status epilepticus has not been determined. Neurotrophins have potent effects on axonal sprouting under certain conditions (Hagg et al., 1990), and previous studies have demonstrated both short and relatively prolonged changes in NGF protein and activity following different types of seizures (Bengzon et al., 1992; Lowenstein, et al., 1993). We therefore investigated further the potential role of NGF in seizure-induced sprouting by determining whether the distribution of NGF-like immunoreactivity was altered within the hippocampus following status epilepticus. Few antibodies to NGF have been useful for determining the distribution of NGF-immunoreactivity within the brain. Recently, however, Conner and colleagues have produced an antibody that appears to demonstrate specific staining for an NGF-like molecule within neural tissue (Conner et al., 1992; Mufson et al., 1994). Within the hippocampus, NGF-like immunoreactivity was found to be restricted to mossy fibers. Similar results with this antibody were found in the control animals used in the present study (Fig. 3A). This is consistent with previous results showing that NGF mRNA is localized predominantly within dentate granule cells in the normal hippocampus (Gall, 1993). The pattern of immunostaining with the antibody was then inspected following seizure-induced injury. Twenty-four days following status epilepticus, there was a redistribution of NGF-like immunoreactivity to include staining of mossy fiber terminals where the mossy fibers had sprouted into the inner margin of the inner molecular layer (Fig. 3B). This staining may represent continued NGF production by dentate granule cells and transport into their terminals. The distribution also corresponded in location to some of the newly sprouted cholinergic axons. Within the sprouted hippocampus, there was also some NGF-like immunoreactivity in scattered glial cells that was not observed in the normal hippocampus (data not shown). It is possible that these anatomical changes, or other long-term alterations in NGF production (Lowenstein et al., 1993) that cannot be evaluated immunocytochemically, may play a role in the system-specific sprouting observed following status epilepticus. It is of note that NGF-like immunoreactivity was also found within cell bodies of BFCNs (Fig. $3 \mathrm{C}$ ). This is likely to be NGF produced in the targets of BFCNs (cortex and hippocampus) that is retrogradely transported.

NGF actions on neurons are mediated by binding and activating the tyrosine kinase receptor trkA (Kaplan et al., 1991). Within the brain, the anatomic distribution of trkA expression is relatively restricted, and in the hippocampus it is sclectivcly localized to cholinergic axons derived from BFCNs (Holtzman et al., 1994, 1995). Following chemoconvulsant-induced status epilepticus, we found that trkA, as measured by immunocytochemistry, remained localized to these axons and was not found in endogenous hippocampal neurons (data not shown). Taken together, these findings suggest that if NGF/trkA interactions play a role in seizure-induced sprouting, then they are likely to be involved specifically in the reorganization of cholinergic axons derived from BFCNs.

\section{$N G F$-specific antibodies diminish cholinergic but not mossy fiber sprouting}

To determine whether NGF modifies mossy fiber or cholinergic sprouting, we investigated whether a specific, NGF-neutralizing

\section{$\leftarrow$}

Figure 2. (bottom). AChE staining in the dentate gyrus before and after convulsant-induced status epilepticus. In the normal dentate gyrus ( $A$ ), there are few cholinergic fibers in the outer aspect of the inner molecular layer (area between arrowheads), and there is a dense plexus in the inner margin of the inner molecular layer (area between arrows). Twenty-four days following pilocarpine-induced status epilepticus (B), there is an increased density of AChE-positive fihers into the inner margin of the inner molecular layer (arrows). When comparing animals that sustained status epilepticus and received either i.c.v.-administered normal goat serum $(C)$ or anti-NGF $(D)$, there was a consistent and clear decrease in the density of cholinergic fibers in the inner margin of the inner molecular layer of anti-NGF-treated animals. Scale bar in $D, 120 \mu \mathrm{m}$. 

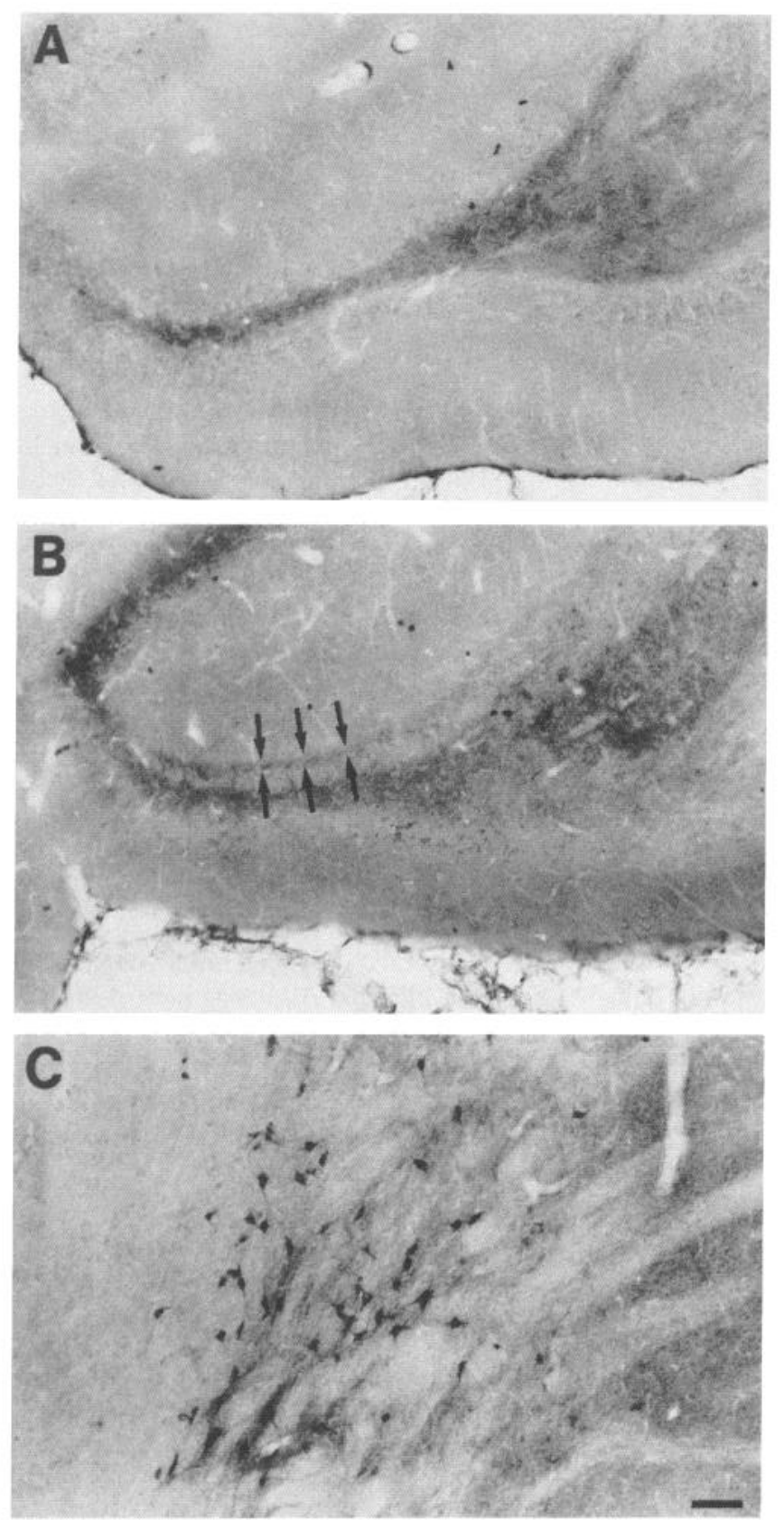

Figure 3. NGF-like immunoreactivity in the dentate gyrus before and after chemoconvulsant-induced status epilepticus. In the normal dentate gyrus $(A)$, NGF-like immunoreactivity appears localized to mossy fibers in the dentate hilus and fibers projecting toward CA3. Twenty-four days following pilocarpine-induced status epilepticus, NGF-like immunoreactivity remains localized to mossy fibers, including those that aberrantly project into the inner molecular layer of the dentate gyrus $(B$, arrows). NGF-like immunoreactivity is also found in cell bodies of magnocellular neurons in the nucleus basalis $(C)$ within presumptive cholinergic neurons. Scale bar in $C$ equals $100 \mu \mathrm{m}$.

antibody (anti-NGF) would modify or block sprouting after infusion into the brain. Several studies in both the PNS (Johnson and Gorin, 1980; Longo et al., 1992) and CNS (Vantini et al., 1989; Van Der Zee et al., 1992; Li et al., 1995) have shown that antibodies to NGF (including the same anti-NGF antibody used in the current study, see Li et al., 1995) can be utilized to disrupt the function of endogenous NGF. In fact, in an in vitro assay,
anti-NGF was found to block most of the NGF-like activity that is induced and persists for weeks to months after kainate-induced status epilepticus (Lowenstein et al., 1993).

Following status epilepticus, sprouting did not become evident by light microscopy and histochemistry for approximately $7 \mathrm{~d}$. A continuous intraventricular infusion of either anti-NGF or normal goat serum via Alzet miniosmotic pumps was therefore started $2 \mathrm{~d}$ following pilocarpine-induced status epilepticus. Control animals that did not have status epilepticus were given infusions of NGF dissolved in vehicle (artificial CSF) or vehicle alone. Twenty-four days after the onset of status epilepticus (22 $\mathrm{d}$ following the implantation of the i.c.v. cannula), animals were sacrificed and their brains were analyzed. Immunocytochemical analysis revealed penetration of the injected antibodies into both the hippocampus and septum (Fig. 4). This suggested that antiNGF should be available to interact with endogenous NGF.

Robust cholinergic sprouting into the inner molecular layer of the dentate gyrus was evident in animals that received infusions of normal goat serum following status epilepticus (Fig. $2 \mathrm{C}$ ). The density of cholinergic fibers present in the inner margin of the inner molecular layer following status epilepticus was similar whether animals received normal goat serum or no treatment (Fig. $2 B, C$ ). In contrast, there was a clear and statistically significant decrease in the density of cholinergic fibers present in the inner margin of the inner molecular layer in animals that received infusions of anti-NGF (Figs. $2 C, D, 5 A$ ). Anti-NGF did not prevent the occurrence of cholinergic sprouting after status epilepticus, but the antibody markedly reduced the extent of sprouting to approximately $26 \%$ of the amount seen in animals that had received normal goat serum (Fig. 5A). Similar to a previous report (Hagg et al., 1990), exogenous administration of NGF to normal animals did not result in any change in the density of cholinergic fibers within the inner molecular layer or other hippocampal structures as assessed by AChE staining (Fig. $5 A$ ). In addition, infusions of anti-NGF had no effects on cholinergic fiber density in animals that did not have status epilepticus (Fig. 5A). These observations suggest that the change in cholinergic fiber density associated with anti-NGF infusions was due to inhibition of sprouting rather than downregulation of the AChE marker.

To assess the effects of anti-NGF on the cholinergic system in the pilocarpine model further, we also looked for effects of anti-NGF on BFCN cell bodies and fibers within the basal forebrain. In animals that had status epilepticus and received normal goat serum, there was an increase in the mean cross-sectional area of $\mathrm{p} 75^{\mathrm{NGFR}}$-immunoreactive cell bodies in the medial septal nucleus (Fig. $5 A, B$ ) and an apparent increase in the density of

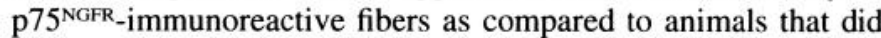
not experience status epilepticus. In animals that had status epilepticus and received anti-NGF, there was also an increase in BFCN cell size; however, the increase was significantly less than that seen in animals treated with normal goat serum (Figs. $5 B$, 6). Qualitatively, p75 NGFR-immunoreactivity fiber staining was also diminished in animals treated with anti-NGF compared to animals treated with normal goat serum. These observations suggest that anti-NGF not only inhibits the seizure-induced remodeling of BFCN axons projecting into the dentate gyrus, but also the structural changes of BFCN cell bodies and axons that are local to the basal forebrain.

In contrast to the effect of anti-NGF on cholinergic sprouting, there was no clear change in the density of sprouted mossy fibers in the inner molecular layer in animals that received anti-NGF 

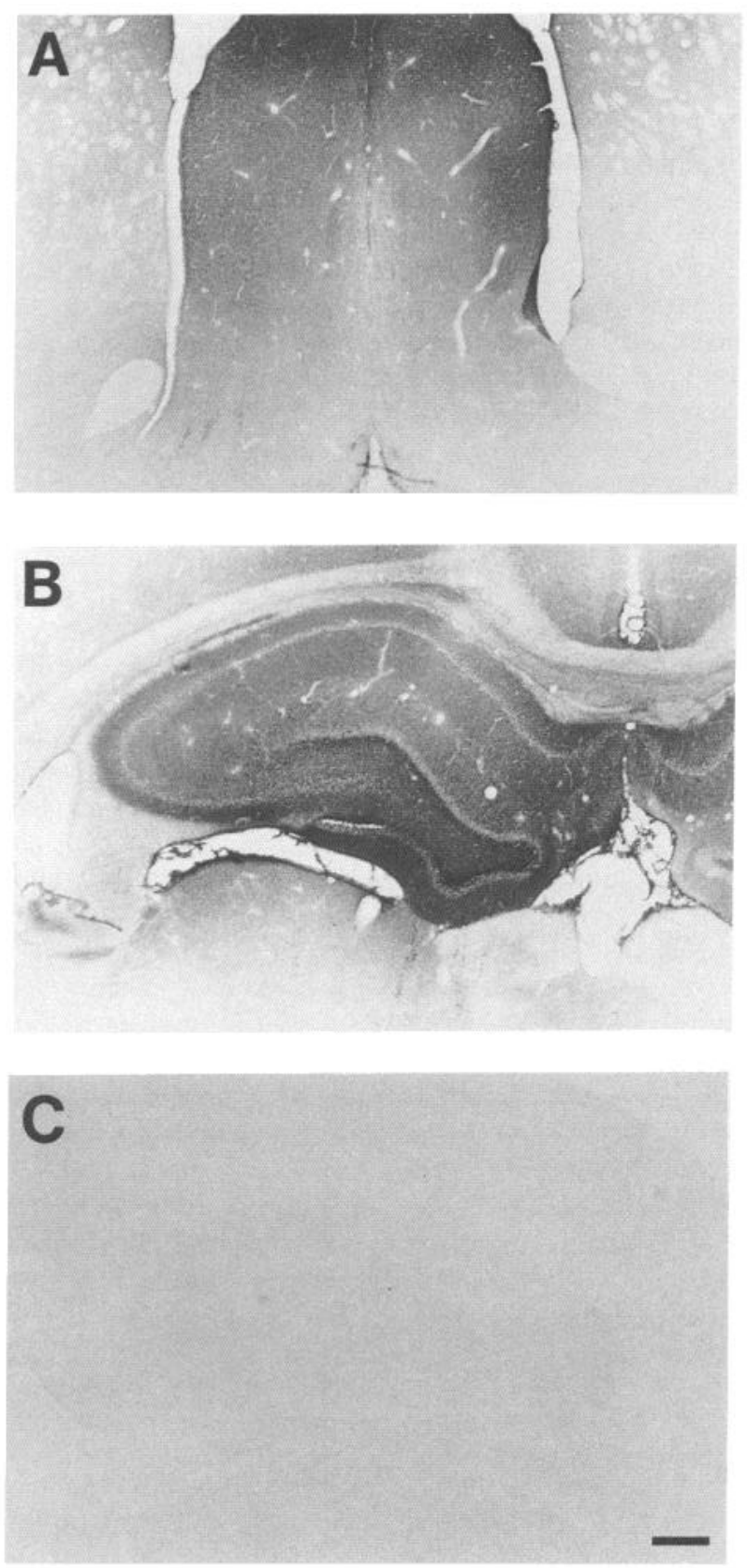

Figure 4. Evidence of penetration of goat $\mathrm{IgG}$ into brain parenchyma. Twenty-four days following the infusion of anti-NGF into the right lateral ventricle, there was strong immunoreactivity for goat IgG throughout the septum $(A)$ as well as the hippocampus $(B)$. Omission of the primary antibody resulted in no discernible immunoreactivity $(C)$. Scale bar in $C, 500 \mu \mathrm{m}$.

compared to those receiving normal goat serum (Fig. 1C,D). The density of mossy fibers present in the inner molecular iayer of anti-NGF-treated animals was slightly greater than in animals receiving normal goat serum, but the change was not statistically significant (anti-NGF $=0.49 \pm 0.03, N=4$; normal goat serum $=0.40 \pm 0.09, N=4, p=0.2$; relative optical densities).

\section{Discussion}

The results in this study show that: (1) both cholinergic fibers and mossy fibers sprout into the inner molecular layer of the dentate gyrus following pilocarpine or kainate-induced status
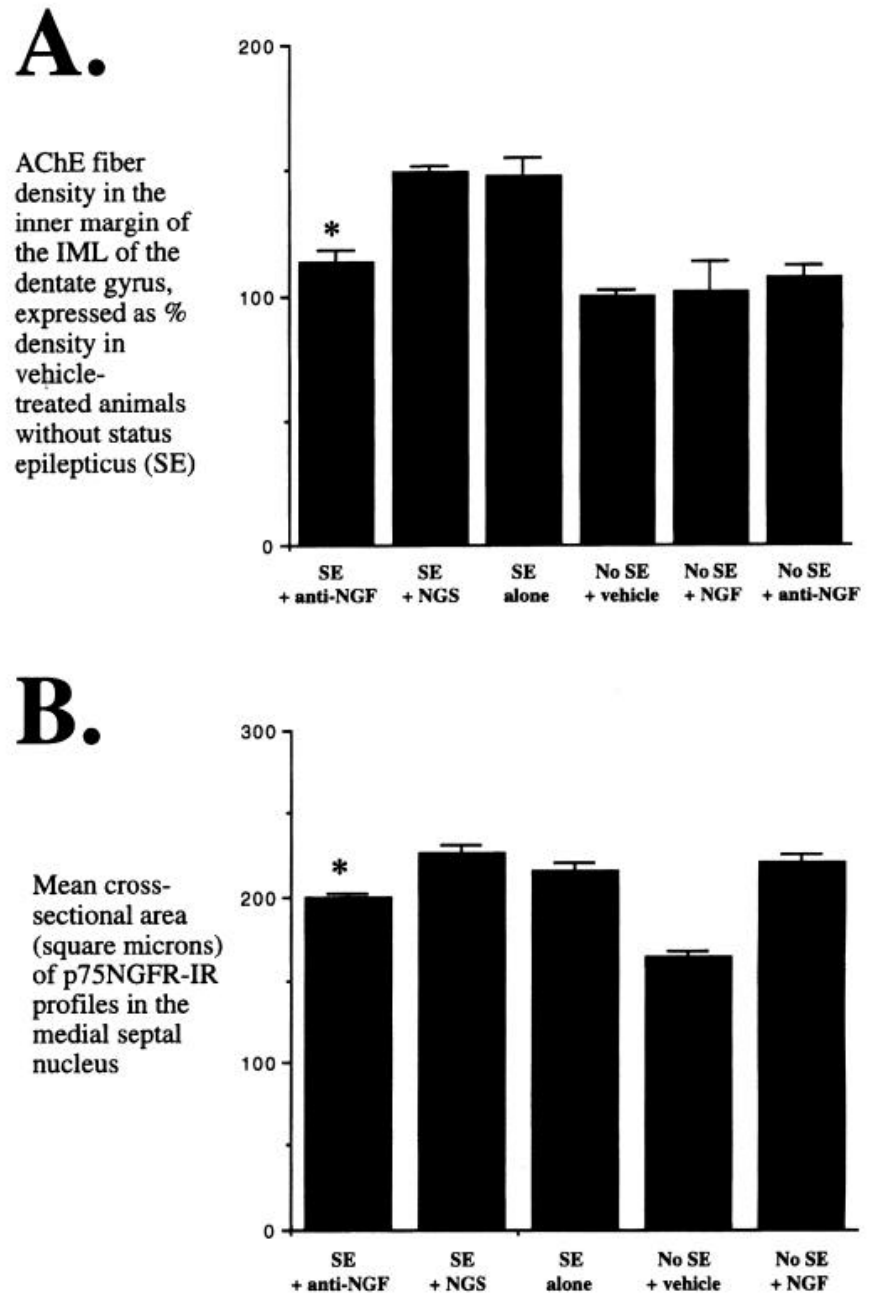

Figure 5. Anti-NGF administered by i.c.v. infusion diminishes cholinergic sprouting and decreases the size of BFCN cell bodies. $A$, In animals that experienced pilocarpine-induced status epilepticus and received anti-NGF, there was a statistically significant decrease $\left({ }^{*} p<\right.$ 0.0001 ) in the density of AChE-stained fibers in the inner margin of the inner molecular layer of the dentate gyrus as compared to animals that had status epilepticus and received normal goat serum (NGS) or no i.c.v. infusion (data are mean \pm SEM; status epilepticus + anti-NGF $=113 \pm 5, N=8$; status epilepticus + NGS $=149 \pm 3, N=3$; status epilepticus alone $=148 \pm 7, N=7$; no status epilepticus + $\mathrm{VEH}=100 \pm 2, N=3$; no status epilepticus $+\mathrm{NGF}=101 \pm 12$, $N=3$; no status epilepticus + anti-NGF $=107 \pm 5, n=2$ ). $B$, In animals that experienced status epilepticus and received anti-NGF, the mean cross-sectional area of p $75^{\text {NGFR }}$-immunoreactive profiles in the medial septal nucleus was significantly less $\left({ }^{*} p<0.0001\right)$ than in animals that sustained status epilepticus alone or in animals that sustained status epilepticus and received NGS. Effects of exogenous NGF on the size of p75 $5^{\mathrm{NGFR}}$-immunoreactive profiles are also shown (data are mean \pm SEM; status epilepticus + anti-NGF $=200 \mu \mathrm{m}^{2} \pm 2.5, n=687, N=$ 6; status epilepticus + NGS $=227 \pm 4.5, n=349, N=3$; status epilepticus alone $=216 \pm 4, n=310, N=3$; no status epilepticus + vehicle $=164 \pm 4 ; n=337, N=3$; no status epilepticus $+\mathrm{NGF}=$ $220 \pm 5, n=320, N=3$ ).

epilepticus, (2) there is an increase in the size of BFCNs during this process, and (3) antibodies to NGF specifically attenuate the cholinergic sprouting and increased size of BFCNs that are associated with seizure-induced injury. These findings suggest that endogenous NGF plays a functional role in mediating permanent structural changes following status epilepticus. To our knowledge, this is the first demonstration that changes in neurotrophin 

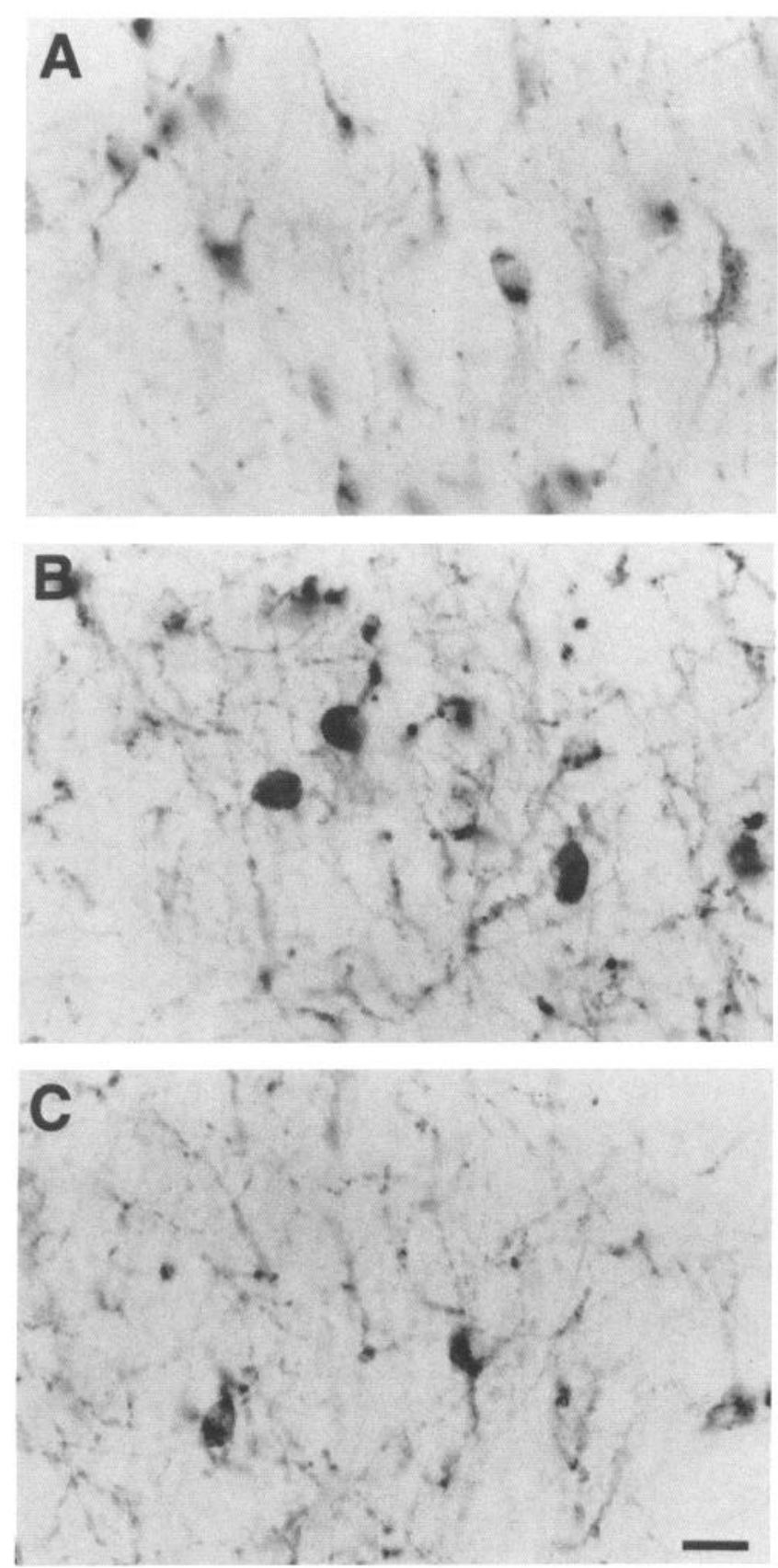

Figure 6. p75 ${ }^{\mathrm{NGFR}}$-immunoreactive fiber and cell body staining is increased following status epilepticus and this staining is diminished by anti-NGF. In the medial septal nucleus of a vehicle-treated animal $(A)$, p $75^{\text {NGFR }}$-immunoreactive fiber staining and cell bodies are shown. In animals that experienced pilocarpine-induced status epilepticus and received i.c.v. infusions of normal goat serum, there was a substantial increase in $\mathrm{p} 75^{\mathrm{NGFR}}$-immunoreactive fiber staining and cell body size $(B)$. The increases in $\mathrm{p} 75^{\mathrm{NGFR}}$-immunoreactive fiber staining and cell body size seen in normal goat serum animals were diminished in animals that received i.c.v. infusions of anti-NGF $(C)$. Scale bar, $25 \mu \mathrm{m}$.

expression following seizures may be directly linked to subsequent structural changes. Because structural changes in the animal models utilized in our studies are similar to those seen in the temporal lobe of humans with chronic epilepsy (Meldrum and Bruton, 1992), our findings suggest that NGF and possibly other neurotrophins may play similar roles in changes found in the human epileptic condition.
The finding that anti-NGF inhibited cholinergic sprouting in the inner margin of the inner molecular layer parallels findings in other models of sprouting in the hippocampus. Reorganization of cholinergic fibers is known to occur in the outer molecular layer of the dentate gyrus following an entorhinal cortex lesion (Lynch et al., 1972). Using this lesion model, Van Der Zee et al. (1992) found that antibodies to NGF diminished sprouting of cholinergic fibers into the outer molecular layer by $75 \%$ compared to lesioned animals that did not receive the antibody. Also, Springer and Loy (1985) have shown that anti-NGF antibodies inhibit the ingrowth of sympathetic fibers into the hippocampus by as much as $80 \%$ following fimbria-fornix transection. It is especially noteworthy that the magnitude of the anti-NGF effect in both of these prior studies was very similar to that observed in ours (i.e., 74\% inhibition). Thus, our results strongly suggest that NGF is having a direct, biological role in mediating the cholinergic sprouting into newly denervated lamina of the dentate gyrus following seizure-induced injury.

The point at which NGF is having a role in the network remodeling following injury remains unknown. However, it appears that an initial stimulus for sprouting following status epilepticus is the loss of neurons in the dentate hilus, which leads to partial deafferentation of the inner molecular layer. Subsequent to this deafferentation, there is sprouting of both mossy fibers and cholinergic fibers into the region. Our results suggest NGF is not sufficient to initiate a growth response in the intact brain, but that it supports the process of neurite growth into vacated synaptic space as well as maintaining other structural changes (cell body size). In support of this view are studies by Hagg et al. (1990) as well as our own observations, which have shown that exogenous and endogenous NGF will result in cholinergic sprouting into the hippocampus, but only if this region has been previously denervated. There are likely to be other molecules having chemoattractant or chemorepellant properties, such as the netrins (Kennedy et al., 1994; Serafini et al., 1994) or the semaphorins (Messersmith et al., 1995; Püschel et al., 1995), which are important in axon pathfinding events and have actions distinct from neurotrophins.

The fact that anti-NGF inhibited cholinergic but not mossy fiber sprouting is consistent with the previously demonstrated distribution of neurotrophin receptors (for review, see Grimes et al., 1993) as well as the specificity of this antibody for NGF (Crutcher et al., 1993; Li et al., 1995). The cell bodies of mossy fibers express trkB and trkC, but not trkA. In contrast, within the hippocampus trkA expression is restricted to cholinergic fibers derived from BFCNs (Holtzman et al., 1994, 1995). Since NGF interacts with trkA but not with trkB or trkC, specifically blocking endogenous NGF should only block effects of NGF on cells expressing trkA. In a recent study, we found that anti-NGF at a dilution of 1:55,000 blocked $50 \%$ of the response to NGF in a neurite outgrowth assay, and fully blocked responses to NGF at a dilution of 1:30,000 ( $\mathrm{Li}$ et al., 1995). Anti-NGF had no effect on BDNF or NT-3 at dilutions higher than 1:250 using a similar assay. In preliminary experiments, we have estimated that the dilution of anti-NGF in the adult rat hippocampus following a 3 week infusion ranges between 1:5000 and 1:20,000 (D.M. Holtzman, unpublished observations). This strongly supports the view that the effects of anti-NGF in this in vivo model were specific for NGF. Although mossy fiber sprouting does not appear to be secondary to NGF, it is certainly conceivable that BDNF, NT-3, or NT-4/5 could contribute to this form of sprouting. The story, however, may be more complicated for mossy 
fibers. Although both trkB and trkC are cxpressed in dentate granule cells, some of this expression is comprised of forms of these receptors that do not appear to lead to functional neurotrophin signaling (Klein et al., 1990; Tsoulfas et al., 1993; Valenzuela et al., 1993). Further experiments with reagents that specifically block the function of neurotrophins other than NGF should allow for the elucidation of the role of these molecules in mossy fiber sprouting.

The physiological consequences of both mossy fiber and cholinergic sprouting and the role of neurotrophins in this process remain uncertain. For mossy fiber sprouting, the formation of new contacts between granule cell axons and granule cell dendrites might create abnormal, recurrent excitatory networks. Although this theory is supported by some data (Tauck and Nadler, 1985; Cronin et al., 1992), other findings suggest the opposite effect (Sloviter, 1992). Attempts to examine directly the physiological effects of cholinergic sprouting following status epilepticus have not been reported. It is very likely that aberrant sprouting of specific systems does alter hippocampal physiology, but the end result of these changes remains to be clarified. Further definition of the role of specific neurotrophins in modulation of both structural as well as physiologic changes may give new insight into both the pathogenesis and treatment of epilepsy.

\section{References}

Babb R, Kupfer W, Pretorius J, Crandall P, I evesque M (1991) Synaptic reorganization by mossy fibers in human epileptic fascia dentata. Neuroscience 42:351-363.

Bengzon J, Soderstrom S, Kokaia Z, Kokaia M, Ernfors P, Persson H, Ebendal T, Lindvall O (1992) Widespread increase of nerve growth factor protein in the rat forebrain after kindling-induced seizures. Neuroscience 53:433-446.

Chao M (1992) Neurotrophin receptors: a window into neuronal differentiation. Neuron 9:583-593.

Conner J, Muir D, Varon S, Hagg T, Manthorpe M (1992) The localization of nerve growth factor-like immunoreactivity in the adult rat basal forebrain and hippocampal formation. J Comp Neurol 319:454462.

Coyle J, Price DL DeLong M (1983) Alzheimer's disease: a disorder of cortical cholinergic innervation. Science 219:1184-1190.

Cronin J, Obenaus A, Houser C, Dudek F (1992) Electrophysiology of dentate granule cells after kainate-induced synaptic reorganization of the mossy fibers. Brain Res 573:305-310.

Crutcher K, Scott S, Liang S, Everson W, Weingartner J (1993) Detection of NGF-like activity in human brain tissue: increased levels in Alzheimer's disease. J Neurosci 13:2540-2550.

Davenport C, Brown W, Babb T (1990) Sprouting of GABAergic and mossy fiber axons in dentate gyrus following intrahippocampal kainate in the rat. Exp Neurol 109:180-190.

Dugich-Djordjevic M, Tocco G, Lapchak P, Pasinetti G, Najm I, Baudry $M$, Hefti F (1992) Regionally specific and rapid increases in brainderived neurotrophic factor messenger RNA in adult rat brain following seizures induced by systemic administration of kainic acid. Neuroscience 47:303-315.

Engel J (1989) Seizures and epilepsy. Philadelphia, PA: Davis.

Ernfors P, Ibáñez C, Ebendal T, Olson L, Persson H (1990a) Molecular cloning and neurotropic activities of a protein with structural similarities to nerve growth factor: developmental and topographical expression in the brain. Proc Natl Acad Sci USA 87:5454-5458.

Ernfors P, Wetmore C, Olson L, Persson H (1990b) Identification of cells in rat brain expressing mRNA for members of the nerve growth factor family. Neuron 5:511-526.

Ernfors P, Bengzon J, Kokaia Z, Persson H, Lindvall O (1991) Increased levels of messenger RNAs for neutrophic factors in the brain during kindling epileptogenesis. Neuron 7:165-176.

Franck J, Pokorny J, Kunkel D, Schwartzkroin P (1995) Physiologic and morphologic characteristics of granule cell circuitry in human epileptic hippocampus. Epilepsia 36:543-558.

Gall C (1993) Seizure-induced changes in neurotrophin expression: implications for epilepsy. Exp Neurol 124:150-166.
Gall C, Isackson P (1989) Limbic seizures increase neuronal production of messenger RNA for nerve growth factor in adult rat forebrain. Science 245:758-761.

Gloor P (1991) Mesial temporal sclerosis: historical background and an overview from a modern perspective. In: Epilepsy surgery (Luders H, ed), pp 689-703. New York: Raven.

Gonlez-Pinilla F, Cotman C, Nieto-Sampedro M (1987) NGF receptor immunoreactivity in rat brain: topographic distribution and response to entorhinal ablation. Neurosci Lett 82:260-266.

Green R, Blume H, Kupferschmid S, Mesulam M (1989) Alterations of hippocampal acetylcholinesterase in human temporal lobe epilepsy. Ann Neurol 26:347-351.

Grimes M, Zhou J, Li Y, Holtzman D, Mobley W (1993) Neurotrophin signalling in the nervous system. Ser. Neurosci 5:239-247.

Hagg T, Vahlsing H, Manthorpe M, Varon S (1990) Nerve growth factor infusion into the denervated adult rat hippocampal formation promotes its cholinergic reinnervation. J Neurosci 10:3087-3092.

Ilefti F, IJartikka J, Salvatierra A, Weincr W, Mash D (1986) Localization of nerve growth factor receptors in cholinergic neurons of the human basal forebrain. Neurosci Lett 69:37-41.

Holtzman D, Li Y, DeArmond \$. McKinley M, Gage F, Epstein C, Mobley W (1992a) A mouse mortel of neurodegeneration: atrophy of basal forebrain neurons in Ts 16 transplants. Proc Natl Acad Sci USA 89:1383-1387.

Holtzman DM, Li Y, Parada LF, Kinsman S, Chen CK, Valletta JS, 7hnu I, Iong I, Mobley WC (1992b) pl40trk mRNA marks NGFresponsive forebrain neurons: evidence that trk gene expression is induced by NGF. Neuron 9:465-478.

Holtzman D, Kilbridge J, Bredt D, Black S, Li Y, Clary D, Reichardt L, Mobley W (1994) NOS induction by NGF in basal forebrain cholinergic neurons: evidence for regulation of brain NOS by a neurotrophin. Neurobiol Dis 1:51-60.

Holtzman D, Kilbridge J, Li Y, Cunningham E, Lenn N, Clary D, Reichardt L, Mobley W (1995) TrkA expression in the CNS: evidence for the existence of several novel NGF-responsive CNS neurons. J Neurosci 15:1567-1576.

Houser C (1992) Morphological changes in the dentate gyrus in human temporal lobe epilepsy. In: The dentate gyrus and its role in seizures (Ribak CE, Gall CM, Mody I, eds), pp 223-234. Amsterdam: Elsevier.

Isackson P, Murray K, Huntsman M, Gall C (1991) BDNF mRNA expression is increased in adult rat forebrain after limbic seizures: temporal patterns of induction distinct from NGF. Neuron 6:937-948.

Johnson E, Gorin P (1980) Dorsal root ganglion neurons are destroyed by exposure in utero to maternal antibody to nerve growth factor. Science 210:916-918.

Kaplan D, Hempstead B, Martin-Zanca D, Chao M, Parada L (1991) The trk proto-oncogene product: a signal transducing receptor for nerve growth factor. Science 252:554-558.

Kennedy T, Serafini T, de la Torre J, Tessier-Lavigne M (1994) Netrins are diffusible chemotropic factors for commissural axons in the embryonic spinal cord. Cell 78:425-435.

Klein R, Conway D, Parada L, Barbacid M (1990) The trkB tyrosine kinase gene codes for a second neurogenic receptor that lacks the catalytic kinase domain. Cell 61:647-656.

Large T, Bodary S, Clegg D, Weskamp G, Otten U, Reichardt L (1986) Nerve growth factor gene expression in the developing rat brain. Science 234:352-355.

Laurberg S, Zimmer J (1981) Lesion-induced sprouting of mossy fiber collaterals to the fascia dentata in developing and adult rats. J Comp Neurol 200:433-459.

Lewis P. Shute C (1967) The cholinergic limbic system: projection to hippocampal formation, medial cortex, nuclei of the ascending cholinergic reticular system, and the subfornical organ. Brain 90:521540.

Li Y, Holtzman D, Kromer L, Kaplan D, Chua-Couzens J, Clary D, Knusel B, Mobley W (1995) Coordinate regulation of trkA and ChAT expression in developing rat basal forebrain: evidence that NGF regulates cholinergic differentiation through p140trk. J Neurosci, in press.

Longo F, Holtzman D, Grimes M, Mobley W (1992) Nerve growth factor: actions in the peripheral and central nervous systems. In: Neurotrophic factors (Fallon J, Loughlin S, eds), pp 209-256. New York: Academic.

Lowenstein D, Seren M, Longo F (1993) Prolonged increases in neu- 
rotrophic activity associated with kainate-induced hippocampal synaptic reorganization. Neuroscience 56:597-604.

Lynch G, Matthews DA, Mosko S, Parks T, Cotman C (1972) Induced acetylcholinesterase-rich layer in rat dentate gyrus following entorhinal lesions. Brain Res 42:311-318.

Margerison J, Corsellis J (1966) Epilepsy and the temporal lobes. Brain 89:499-530.

Mathern G, Kupfer W, Pretorius J, Babb T, Levesque M (1992) Onset and patterns of hippocampal sprouting in the rat kainate seizure model: evidence for progressive cell loss and neo-innervation in regio inferior and superior. Dendron 1:69-84.

Meldrum B, Bruton C (1992) Epilepsy. In: Greenfield's neuropathology (Adams J, Duchen L, eds), pp 1246-1283. New York: Oxford UP.

Mello L, Cavalheiro E, Tan A, Kupfer W, Pretorius J, Babb T, Finch D (1993) Circuit mechanisms of seizures in the pilocarpine model of chronic epilepsy: cell loss and mossy fiber sprouting. Epilepsia 34: 985-995.

Messersmith E, Leonardo E, Shatz C, Tessier-Lavigne M, Goodman C, Kolodkin A (1995) Semaphorin III can function as a selective chemorepellant to pattern sensory projections in the spinal cord. Neuron 14:949-959.

Mobley W, Rutkowski J, Tennekoon G, Gemski J, Buchanan K, Johnston $M$ (1986) Nerve growth factor increases choline acetyltransferase activity in developing basal forebrain neurons. Mol Brain Res $1: 53-62$.

Mufson E, Conner J, Varon S, Kordower J (1994) Nerve growth factorlike immunoreactive profiles in the primate basal forebrain and hippocampal formation. J Comp Neurol 341:507-519.

Nadler J, Perry B, Cotman C (1980) Selective reinnervation of hippocampal area $\mathrm{CA} 1$ and the fascia dentata after destruction of CA3 CA4 afferents with kainic acid. Brain Res 182:1-9.

Olton D, Markowska A, Voytoko M, Givens B, Gormon L, Wenk G (1991) Basal forebrain cholinergic system: a functional analysis. Adv Exp Med Biol 295:353-372.

Paxinos G, Watson C (1986) The rat brain in stereotaxic coordinates. Sydney: Academic.

Phillips H, Hains J, Laramee G, Rosenthal A, Winslow J (1990) Widespread expression of BDNF but not NT-3 by target areas of basal forebrain cholinergic neurons. Science 250:290-294.

Pico R, Gall C (1994) Hippocampal epileptogenesis produced by elec- trolytic iron deposition in the rat dentate gyrus. Epilepsy Res 19:2736.

Püschel A, Adams R, Betz H (1995) Murine semaphorin D/collapsin is a member of a diverse gene family and creates domains inhibitory for axonal extension. Neuron 14:941-948.

Serafini T, Kennedy T, Galko MJ, Mirzayan C, Jessell T, Tessier-Lavigne $M$ (1994) The netrins define a family of axon outgrowth-promoting proteins homologous proteins homologous to $C$. elegans UNC-6. Cell 78:409-424.

Sloviter R (1982) A simplified Timm stain procedure compatible with formaldehyde fixation and routine embedding of rat brain. Brain Res Bull 8:771-774.

Sloviter R (1992) Possible functional consequences of synaptic reorganization in the dentate gyrus of kainate-treated rats. Neurosci Lett 137:91 96.

Snider W (1994) Functions of the neurotrophins during nervous system development: what the knockouts are teaching us. Cell 77:627-638.

Springer J, Loy R (1985) Intrahippocampal injections of antiserum to nerve growth factor inhibit sympathohippocampal sprouting. Brain Res Bull 15:629-634.

Tauck D, Nadler J (1985) Evidence of functional mossy fiber sprouting in hippocampal formation of kainic acid-treated rats. $J$ Neurosci 5:1016-1022.

Thoenen $H$ (1991) The changing scene of neurotrophic factors. Trends Neurosci 14:165-170.

Tsoulfas P, Soppet D, Escandon E, Tessarollo L, Mendoza-Ramirez J-L, Rosenthal A, Nikolics K, Parada L (1993) The rat trkC locus encodes multiple neurogenic receptors that exhibit differential response to neurotrophin-3 in PC12. Neuron 10:975-990.

Valenzuela D, Maisonpierre P, Glass DJ, Rojas E, Nunez L, Kong Y, Gies D, Stitt T, Ip N, Yancopoulos G (1993) Alternative forms of rat trkC with different functional capabilities. Neuron 10:963-974.

Van Der Zee C, Fawcett J, Diamond J (1992) Antibody to NGF inhibits collateral sprouting of septohippocampal fibers followin $\mathrm{g}$ entorhinal cortex lesion in adult rats. J Comp Neurol 326:91-100.

Vantini G, Schavo N, DiMartino A, Polato P, Triban C, Callegaro L, Toffano G, Leon A (1989) Evidence for a physiological role for nerve growth factor in the central nervous system of neonatal rats. Neuron 3:267-273.

Yan Q, Johnson E (1988) An immunohistochemical study of nerve growth factor receptor in developing rats. J Neurosci 8:3481-3498. 